ORIGINAL ARTICLE

\title{
A community level syphilis prevention programme: outcome data from a controlled trial
}

\author{
M W Ross, N S Chatteriee, L Leonard
}

Sex Transm Infect 2004;80:100-104. doi: 10.1136/sti.2003.006171

See end of article for authors' affiliations

Correspondence to:

M W Ross, WHO Center

for Health Promotion and

Prevention Research,

School of Public Health,

University of Texas, PO

Box 20036, Houston, TX

77225, USA;

mross@sph.uth.tmc.edu

Accepted for publication 14 September 2003

\begin{abstract}
Objectives: This study investigated the impact of a small media campaign to reduce syphilis through testing, treatment, and condom use in two urban predominantly African-American communities with high syphilis rates.

Methods: Data were collected from intervention and comparison zip codes using cross sectional street intercept interviews at baseline and 2 years later $(n=1630)$ following a small media syphilis prevention campaign with role model story posters, billboards, and other merchandise. Community businesses and a community based organisation served as partners, distributing condoms and small media.

Results: Comparing intervention with comparison zip codes, there were significant increases in condom use in last sexual act, and some aspects of knowledge of syphilis. However, there was significant cross contamination of media impact, with respondents in the comparison zip code seeing an average of two media items compared with three in the intervention zip code. Media exposure was associated with significant increases in knowledge of syphilis, testing, and condom use.

Conclusions: Targeted community based small media interventions using community partners for distribution are effective in increasing syphilis knowledge, testing, and condom use.
\end{abstract}

W hile syphilis has been declining in the United States since 1995, it is unevenly distributed, with rates being highest in the south east of the country, and in urban areas, ${ }^{1}$ although rates have dropped since the most recent peak in 1989-90. ${ }^{2}$ The Healthy People 2000 objective for syphilis cases was 4/100 000; in Houston, Texas, over half of the city's primary and secondary syphilis cases were concentrated in 15 of the city's more than 100 zip codes. Prevalence of primary and secondary syphilis in these 15 zip codes was 62/100 000 to 101/ $100000 .^{34}$ The CDC targeted syphilis as one of the diseases for elimination in the next decade. Elimination, however, will require community targeted programmes among other approaches. $^{5}$

Community customisation of syphilis elimination programmes is necessary. Ecological analysis revealed that sociodemographic characteristics accounted for $71 \%$ of the variation in syphilis rates among US counties. Highly correlated characteristics were percentage of black population, southern location, percentage of urban population, percentage Hispanic population, and percentage of births to women younger than 20 years.

Reasons for the increased rates of HIV and other STIs among African-Americans in the south eastern United States remain unclear. However, in focus group interviews, rural African-American respondents reported pervasive economic and racial disadvantage, lack of community recreation, boredom, and resultant substance abuse. Many perceived a shortage of black men because of their higher mortality and incarceration rates compared with whites, and believed this male shortage to be partly responsible for the concurrent sexual partnerships that they perceived as widespread. Thus, contextual features including racism, discrimination, limited employment opportunity, and resultant economic and social inequity may promote sexual patterns that transmit STIs including syphilis. ${ }^{67}$ Only through community based efforts that pay attention to local contextual features can a national syphilis elimination programme become more effective in achieving its goals.
There have been few community based STI prevention programmes. Job-Spira et $a l^{8}$ assigned six French departments to intervention or control conditions, with the intervention being a media campaign to reduce genital discharge through seeking treatment, education of local physicians, and increased condom availability. Their randomised community trial ${ }^{9}$ over 5 months did not show significant differences. Arnold and Cogswell ${ }^{10}$ distributed condoms in a large eastern US city to men aged 12-24 for 3 months. Distribution sites included barbershops, food stores and restaurants, and pool halls. From a baseline of $<20 \%$ condom use, by week $4,60 \%$ of respondents had used a condom in the past week, and by week 12, all sampled respondents had used a condom from $62 \%$ at baseline. Condom use at last intercourse increased from 20\% to $91 \%$ : success was attributed to the consumer acceptability of small business distributors and the enthusiasm of the shopkeepers. In community demonstration projects to reduce HIV infection risk behaviours in five US cities and five matched comparison communities, ${ }^{11}$ role model stories ${ }^{12}$ were distributed, along with condoms and bleach, by community members over 3 years. Data indicated that condom use significantly increased with both main and casual partners and there was significantly increased condom carriage in the intervention communities.

The APPLE project, a community based programme to prevent perinatal HIV infection by preventing infection in women, tested a primary prevention model which used street outreach and community targeted small media materials to increase the use of condoms. It was evaluated using a two community, time series, quasi-experimental design with annual street surveys. Norms reflecting social acceptability of condoms were more positive among women in the intervention community, and condom use at last sexual encounter was significantly higher in the intervention community, and among women exposed to either small media or small media and street outreach. ${ }^{13}$

To assess the feasibility of community based syphilis prevention, we carried out a 2 year community intervention 
with intervention and comparison communities based on the distribution of role model stories and other small media and using volunteer local small businesses to distribute messages and condoms. The study, based on social learning theory, ${ }^{12}$ was a partnership between university, city health department, and a community based organisation. The intervention had four aims: (1) to increase knowledge about syphilis and its transmission; (2) to increase syphilis screening and treatment; (3) to increase use of condoms; (4) to decrease numbers of sexual partners; and (5) to assess media exposure-response relations. Aim (5) provides an alternative measure of small media exposure-response in the event of significant contamination in the comparison community. The study was approved by the university human subjects protection committee.

\section{METHODS}

\section{Community selection}

Intervention and comparison communities were selected from the 12 zip codes in Houston/Harris County with the highest syphilis rates (>300/100 000 in 1994). The syphilis affected neighbourhoods were distributed in a belt slightly east of the city centre and were poor, low income neighbourhoods, with high rates of crime, drug addiction, and other STIs. The two zip codes were at minimum 2 miles $(3.2 \mathrm{~km})$ (average 5 miles $(8 \mathrm{~km}))$ apart and separated by a major freeway. The 1994 syphilis rate in the intervention zip code was 470, for the comparison zip code 523/100 000, and both were predominantly $(>85 \%)$ African-American. Socioeconomic characteristics of the intervention community (geographically defined by zip code) are compared to the rest of Houston in table 1. Characteristics of the intervention and control zip codes appear in table 2 .

\section{Intervention activities}

The intervention was modelled on the HIV community demonstration projects. Extensive formative research, including use of the community identification (CID) process comprising system personnel interviews, interviews with those interacting with people with syphilis, gatekeeper interviews, and key participant interviews, as well as focus groups, informed the intervention. ${ }^{14-17} \mathrm{~A}$ project name and logo competition with offer of a cash award was launched in the intervention community, and the selected logo (with few modifications by a graphics designer) was used on all project materials including condom/lubricant packages. Role model stories were developed through initial qualitative and quantitative interviews (pre-baseline survey ${ }^{15}$ ) and focus groups with members of the intervention community. From these, role model stories that contained these messages, and other small media materials (five different role model brochures and posters, coasters, matchbooks, T-shirts, videos, and billboards) were developed. Role model stories covered busy professionals ("With such a full life, who wants to worry about syphilis"), mothers on welfare ("I may be on welfare but I'm still going to be a good mother"), local culture ("Cowboys always play it safe (and they never forget their hats)"), materno-fetal transmission ("I got syphilis from my parents"), and refusers ("I won't use no condoms. I won't stop sleeping around. What y'all gonna DO about it?"). Each contained the project logo in colour and the message "Get tested. Get treated. Use condoms" which appeared on all materials. Stories were authentic and told in the language of the storytellers from the intervention community, and described how the role models were changing, or planning to change, their behaviours consistent with the aims of the study. Role model photographs were in black and white: professional models were used. The community partner which provided HIV related outreach and testing and also syphilis testing and was located in the intervention community, had been operational for over 10 years, and was well known and respected in the community. Community project staff were employed by the community partner and physically based in their storefront premises, and business partnerships were voluntary and unpaid.

Billboards were placed at six points around the intervention community and the displays changed at 8 week intervals. Many displays were topical, and the syphilis prevention and condom use messages were woven around an event or special day-for example, for Valentine's Day, Halloween, 1 April, 4 July, Thanksgiving, and New Year. For 2 years, project staff visited the community business partners replacing materials biweekly. In the comparison community, provision only of condoms from 10 businesses, using a different project name and logo, was provided.

\section{Business partners}

Community businesses were approached by the project workers and the project explained. Thirty intervention businesses were initially selected by locating them across the map of the intervention community and approached to solicit voluntary participation. Outreach workers had samples of all the materials and shopkeepers or service providers could choose those they wished to stock. Bowls of condom/ lubricant packages were placed on counters or similar places accessible to the public without need to request them. Most residents of the community were no more than four blocks from a community business partner. After 6 months, an additional 20 businesses approached the project staff and requested to be part of the project, and by the end of the intervention, there were 50 community business partners in the intervention zip code. Ten businesses dropped out or were removed from the partners list for various reasons from closure to project workers discovering that some business owners were selling the condoms to clients.

\section{Data collection}

The interview instrument was developed from the initial interviews and piloted on a street intercept sample of 10 in the intervention community. In early 1998, 808 street intercept interviews were conducted in each of the two zip codes. Interviews were conducted by an outreach worker

\begin{tabular}{|c|c|c|}
\hline & $\begin{array}{l}\text { Third ward (intervention zip } \\
\text { code) }\end{array}$ & City of Houston \\
\hline $\begin{array}{l}\text { Total population } \\
\text { Median household income } \\
\text { Proportion below federal poverty level } \\
\text { Proportion of children who live in poverty } \\
\text { Proportion of high school dropouts }\end{array}$ & $\begin{array}{l}29940 \\
\$ 11800 \\
41 \% \\
61 \% \\
61 \%\end{array}$ & $\begin{array}{l}1654348 \\
\$ 26621 \\
17 \% \\
30 \% \\
17 \%\end{array}$ \\
\hline
\end{tabular}




\begin{tabular}{|c|c|c|c|c|}
\hline \multirow[b]{2}{*}{ Sociodemographic/sexual variables } & \multicolumn{2}{|c|}{ Baseline ( $n=808)$} & \multicolumn{2}{|c|}{ Post-intervention ( $n=822$ ) } \\
\hline & $\begin{array}{l}\text { Intervention } \\
(n=419)\end{array}$ & $\begin{array}{l}\text { Control } \\
(n=389)\end{array}$ & $\begin{array}{l}\text { Intervention } \\
(\mathrm{n}=422)\end{array}$ & $\begin{array}{l}\text { Control } \\
(n=400)\end{array}$ \\
\hline \multicolumn{5}{|l|}{ Sex } \\
\hline Male & $239(57 \%)$ & $219(56 \%)$ & $286(68 \%)$ & $242(61 \%)$ \\
\hline \multicolumn{5}{|l|}{ Race } \\
\hline African-American & $357(85 \%)$ & $355(91 \%)$ & 408 (97\%) & 373 (93\%) \\
\hline White & $32(8 \%)$ & $15(4 \%)$ & $2(0.5 \%)$ & $2(0.5 \%)$ \\
\hline Employed & $244(58 \%)$ & $233(60 \%)$ & $224(53 \%)$ & $230(58 \%)$ \\
\hline Full time jobs & 181 (75\%) & $163(71 \%)$ & $168(75 \%)$ & $186(81 \%)$ \\
\hline Lives with sex partner & $123(29 \%)$ & $138(36 \%)$ & $130(31 \%)$ & $160(40 \%)$ \\
\hline Marital status-single & $255(61 \%)$ & $215(56 \%)$ & $245(58 \%)$ & $214(54 \%)$ \\
\hline Number of sex partners in last 4 weeks & 2.67 & 2.39 & .79 & .91 \\
\hline Times had sex in last 4 weeks & 15.84 & 13.83 & 8.12 & 9.22 \\
\hline Number of those times used condoms & 5.76 & 5.15 & 3.18 & 2.67 \\
\hline Proportion of times used condoms & .42 & .40 & .44 & .38 \\
\hline
\end{tabular}

from the community based partner located in the intervention community. Respondents who were $\geqslant 18$ years old were approached in a variety of locations, including parking lots or sidewalks outside local businesses, bus stops, drug corners, and front yards. We used a seven page semistructured survey instrument to elicit information about sociodemographic characteristics, knowledge of syphilis, perceptions of disease severity, exposure to messages about syphilis, awareness of local screening and treatment services, sexual behaviour (including last sexual encounter), and drug use. There was no compensation for completing the interview. To obtain a second comparable cross sectional sample, the process was repeated in early 2000, when 822 street intercept interviews were conducted using identical methodology and sampling.

\section{Data analysis}

Data were analysed using SPSS 10.0. Comparisons between unadjusted data by zip code were by $t$ test (independent samples, separate variance estimates) for interval or ratio data and $\chi^{2}$ tests with Yates's correction for discontinuity where appropriate for ordinal data. Comparisons on the outcome indices (testing, treatment, and condom use) were between the intervention and control community samples, and used ANOVA controlling for age, years of schooling, marital status and, for condom use, number of sexual partners. Data were examined for normality and $\log$ transformed where there was significant deviation from normality.

Given the potential for cross community contamination, we also carried out analyses of degree of exposure to the small media materials to provide evidence for exposureresponse relations. For differences between those who had and had not seen the project media, $\chi^{2}$ tests as above were used. Pearson correlation coefficients were used to compare the total knowledge score (the sum of correct responses to all the knowledge items) to whether the respondents had seen the media or not. Significance levels were set at 5\%, two tailed, for all analyses.

\section{RESULTS}

Results appear in tables 1-3 and figure 1. Results by zip code controlled for baseline age, years of schooling, marital status and, for condom use, number of sexual partners. The project assumed that there would be little overlap in exposure to the media products between the intervention and comparison zip codes: however, in the intervention zip code, an average of 2.99 (SD 3.74) products were seen by $70.8 \%$ of the sample, while in the comparison zip code 2.04 (3.00) products were seen by $64.5 \%$ of the sample (both $\mathrm{p}<0.05$ ). Acknowledging this possibility, we also measured small media exposure as an alternative strategy. In table 3, data illustrate the significant associations between outcome variables (knowledge questions reflect correct response percentage) by those who did and did not report seeing any media products as a measure of exposure response. Analysis with and without white respondents included did not alter the magnitude or significance of results.

\section{DISCUSSION}

This study was based on the premise that there would be relatively wide differences in exposure to the small media between the randomly selected intervention and control zip codes. However, the data indicate that while the differences in number of products seen and proportion of the postintervention sample who had seen them were significant, there was substantial overlap. There was only a $5 \%$ difference in the proportion in each zip code who reported seeing at least one of the media, and the mean difference in number seen was only one item. Thus, any significant results occur in
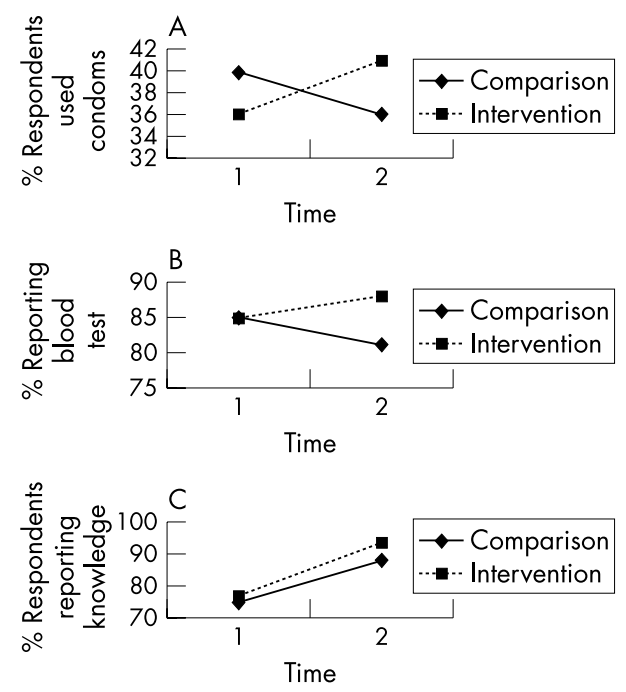

Figure 1 Adjusted frequencies of significant outcome variables preintervention and post-intervention in intervention and control communities - controlling for age, years of schooling, marital status and, for condom use, number of sexual partners. (A) Used condoms in last sexual act. (B) What is the best test to detect syphilis? (C) Sores/ulcers are a warning sign of syphilis. All $p<0.05$. 


\begin{tabular}{|c|c|c|c|}
\hline \multirow{3}{*}{$\begin{array}{l}\text { Variable } \\
\text { Intervention zip code } \\
\text { Control zip code }\end{array}$} & \multicolumn{2}{|c|}{ Number of products seen } & \multirow{3}{*}{$\begin{array}{l}\text { Significance } \\
0.000\end{array}$} \\
\hline & 2.99 (3.74) & & \\
\hline & $2.04(3.00)$ & & \\
\hline & Saw $(\%)^{*}$ & \multicolumn{2}{|c|}{ Did not see (\%) } \\
\hline Intervention zip code & 70.8 & 29.2 & \\
\hline \multirow[t]{2}{*}{ Control zip code } & 64.5 & 35.2 & 0.02 \\
\hline & Saw (\%) yes & \multicolumn{2}{|c|}{ Did not see $(\%)$ yes } \\
\hline Heard of syphilis & 96.7 & 92.2 & 0.000 \\
\hline Ever had a syphilis test & 52.7 & 39.9 & 0.000 \\
\hline Ever used a condom & 88.8 & 75.5 & 0.000 \\
\hline Used a condom at last intercourse & 44.0 & 33.2 & 0.000 \\
\hline High/drunk last time had sex & 31.7 & 43.0 & 0.000 \\
\hline Transmitted by skin contact & 42.8 & 36.5 & 0.04 \\
\hline Transmitted by needle sharing & 82.5 & 71.0 & 0.000 \\
\hline Transmitted from mother to fetus & 89.0 & 81.5 & 0.000 \\
\hline Transmitted from toilet seats & 38.8 & 47.8 & 0.003 \\
\hline There are warning signs of syphilis & 76.0 & 70.6 & 0.04 \\
\hline $\begin{array}{l}\text { Blindness is a warning sign of } \\
\text { syphilis }\end{array}$ & 72.6 & 61.8 & 0.001 \\
\hline Śkin spots are a warning sign & 78.5 & 72.8 & 0.06 \\
\hline $\begin{array}{l}\text { Possible for person to carry syphilis } \\
\text { without warning signs }\end{array}$ & 67.0 & 59.9 & 0.04 \\
\hline $\begin{array}{l}\text { Possible to get re-infected } \\
\text { Correlation between number of } \\
\text { products seen and total knowledge } \\
\text { of syphilis }\end{array}$ & 12.0 & $\begin{array}{l}5.5 \\
r=0.12\end{array}$ & $\begin{array}{l}0.001 \\
0.001\end{array}$ \\
\hline
\end{tabular}

the face of this substantial contamination of media to the comparison community, which would have the effect of reducing the probability of obtaining significant differences on outcome variables. Thus we also look at degree of small media exposure in relation to outcomes as a contamination free measure supporting community comparisons.

It is apparent that from the high baseline levels of knowledge it would be difficult to achieve a significant knowledge increase. However, knowledge of the type of test necessary, the fact that a sore or ulcer is a warning sign of infection, and the fact that syphilis can be successfully treated, all points based on misconceptions from the pilot work, significantly increased in the intervention community. One of the most significant behaviours targeted in the programme message ("Get tested. Get treated. Use condoms") was condom use, and there was a significant increase in adjusted condom use for the last sex act proportions between the intervention and the comparison communities, despite the availability of condom packages in community businesses in the comparison community. Condoms were distributed in the comparison community because condom distribution is a standard treatment: withholding them would be unethical. These data suggest that it is not just condom availability but the concurrent small media campaign that encouraged and reinforced the efficacy of both testing and treatment using role models, which led to the increase in condom use. Thus, availability seems to be a necessary but not sufficient cause for an increase in condom use.

The possibility of contamination between communities was foreseen and, consequently, we also measured the exposure-response relations between small media and outcome variables to overcome it. Where contamination is possible, biasing towards null hypotheses, we recommend this strategy to provide alternative or supporting evidence for the impact of small media.

In the CDC AIDS Community Demonstration Projects, ${ }^{11}$ exposure peaked at 54\% at month 27. In the AIDS Prevention for Pediatric Life Enrichment (APPLE) project, ${ }^{13}$ after 2 years of intervention, name recognition was $40 \%$, contact with media materials was $63 \%$, and contact with outreach workers was $36 \%$. Here, the peak for small media materials was $71 \%$ (65\% in the comparison zip code). The difference between the respective zip codes of three versus two small media recalled suggests that even relatively small numbers of products may induce significant change. Analysis by those who had and had not seen the project small media confirmed that, over both zip codes, there were significant differences in those who had heard of syphilis, had a syphilis test, ever used a condom, and used a condom at last intercourse. Breaking down data by those who had and had not seen the media confirms that it was the small media that were largely responsible for the changes in knowledge and behaviour.

How much did the "Partners in health" network (local businesses and service agencies) contribute to the increase in knowledge and condom use in the intervention zip code? We cannot answer definitively. Would just the distribution of condoms and flyers by outreach workers or volunteers on street corners have worked equally well? Maybe, but the qualitative interviews and the process evaluation that were conducted in the intervention community with our community partners and local business and service agency representatives clearly revealed their interest, enthusiasm, and commitment to the cause of improving the health of their neighbourhood. From a behavioural intervention model or social learning standpoint, it is likely that seeing business leaders supporting the campaign and the placement of condoms and educational materials in prominent and easily accessible places in the community not only served as a cue to action, but also connected the information and motivations in the role model stories to real local community businesses and leaders.

These data confirm the findings of the CDC AIDS community demonstration projects that culturally appropriate small media distribution in conjunction with community based condom distribution can, compared with a comparison community, increase the knowledge on which testing and prevention of syphilis are based, and condom use in the last 


\section{Key messages}

- Small media (messages and role model stories) have a positive impact on syphilis risk behaviour (condom use) and knowledge about syphilis

- Involvement of community businesses as "partners in health" provides community support and avenues for condom and message dissemination

- Relatively minor differences in small media exposure are associated with significant impacts on STD related knowledge and behaviours

- Where contamination of the comparison community by the intervention message is possible, measuring individual exposure to small media messages is essential to determine exposure-response relations

sexual act. To eliminate syphilis, a CDC goal, then the efficacy of low cost community interventions for specific STDs such as syphilis need to be shown. Development and distribution of small media as demonstrated in this programme increase the relevance of the health messages to the affected community members and allow for inputs of the most important stakeholder in this syphilis elimination effort: people in poorer, more disenfranchised neighbourhoods affected by or at high risk of acquiring syphilis. These data offer encouragement that small media campaigns, in close partnership with targeted communities (both community based organisations and businesses), can significantly impact both knowledge and behaviour, that are relevant to the elimination of syphilis.

\section{ACKNOWLEDGEMENTS}

This research was supported by a grant, "Innovation in Syphilis Prevention in the United States", cooperative agreement R30/ CCR612016, funded by Centers for Disease Control and Prevention, Atlanta, GA, USA. We thank our partners at Over the Hill, Inc, Lawrence Duncan, Leisha Grant, and Gertie Oliver; the City of Houston, John Paffel, Cheryl Cunningham, and Glenda Gardner; and the University of Texas, Lu-Yu Hwang, MD, and Jan Risser, PhD, for their dedicated and untiring work on this project. We also thank our colleagues at CDC, including Jo Valentine, MSW, Michael St Louis, MD, Lynne Finelli, Dr PH, and Bill Levine, MD, MSc, and our colleagues in the Cooperative Agreement in Columbia, SC, Jackson, MS, and New Orleans, LA, USA.

\section{CONTRIBUTORS}

MWR and LL were principal investigators of the study, and NC was project officer; MWR wrote the first draft and LL and NC amended and added to the manuscript, and NC carried out the major part of the data analyses, with MWR carrying out the minor part.

\section{Authors' affiliations}

M W Ross, WHO Center for Health Promotion and Prevention Research, School of Public Health, University of Texas, PO Box 20036, Houston, TX 77225, USA

N S Chatteriee, Health and Safety Division, Texas A\&M University, TAMU 4243, College Station, TX 77843-4243, USA

L Leonard, Department of International Health, School of Public Health and Hygiene, Johns Hopkins University, 615 North Wolfe St \#7142,

Baltimore, MD 21205, USA

\section{REFERENCES}

1 Kilmarx PH, Zaidi AA, Thomas JC, et al. Sociodemographic factors and the variation in syphilis rates among US counties, 1984 through 1993: an ecological analysis. Am J Public Health 1997;87:1937-43.

2 Nakashima AK, Rolfs RT, Flock ML, et al. Epidemiology of syphilis in the United States, 1941-1993. Sex Transm Dis 1996;23:16-23.

3 Maruti S, Ross MW, Hwang L-Y, et al. The epidemiology of early syphilis in Houston, Texas 1994-1995, gender differences in rate and presentation. Sex Transm Dis 1997;24:475-80.

4 Risser JMH, Hwang L-Y, Risser WL, et al. The epidemiology of syphilis in the waning years of an epidemic: Houston, Texas, 1991-1997. Sex Transm Dis 1999;26:121-6.

5 Aral SO. Elimination and reintroduction of a sexually transmitted disease: lessons to be learned? Am J Public Health 1999;89:995-7.

6 Adimora AA, Schoenbach VJ, Martinson FE, et al. Social context of sexual relationships among rural African Americans. Sex Transm Dis 2001;28:69-76

7 Aral SO. The social context of syphilis persistence in the southeastern United States. Sex Transm Dis 1996;23:9-15.

8 Job-Spira N, Meyer L, Bouvet E, et al. The prevention of sexually transmitted diseases which affect fertility: methodological problems and initial results. Eur J Obstet Gynecol Reprod Biol 1988;27:157-64.

9 Meyer L, Job-Spira N, Bouyer J, et al. Prevention of sexually transmitted diseases: a randomized community trial. J Epidemiol Commun Health 1991;45: 152-8.

10 Arnold CB, Cogswell BE. A condom distribution program for adolescents: the findings of a feasibility study. Am J Public Health 1971;61:739-50.

11 The CDC AIDS Community Demonstration Projects Research Group. Community-level HIV intervention in 5 cities: final outcome data from the CDC AIDS Community Demonstration Projects. Am J Public Health 1999;89:336-45

12 Bandura A. Social foundations of thought and action: a social cognitive theory. Englewood Cliffs, NJ: Prentice-Hall, 1986.

13 Santelli JS, Celentano DD, Rozsenich C, et al. Interim outcomes for a community-based program to prevent perinatal HIV transmission. AIDS Educ Prev 1995; 7:210-20

14 Leonard L, Ross MW. The last sexual encounter: the contextualization of sexual risk behavior. Int J STD AIDS 1997;8:643-5.

15 Leonard L, Chatterjee N, Ross MW. Preventing syphilis: lessons from a survey of two inner-city communities in Houston, Texas. J Health Care for the Poor and Underserved 1999;10:362-75.

16 Baseman J, Ross MW, Williams ML. Sale of sex for drugs and drugs for sex: an economic context of sexual risk behavior for STDs. Sex Transm Dis 1999;26:444-9.

17 Chatteriee N, Leonard L, Ross MW. The role of private physicians in STD control in two inner-city communities in Houston, Texas. J Public Health Manage Pract 1999;5:34-9. 